ORIGINAL STUDY

\title{
Difficulties in the surgical management of head and neck cancer patient
}

\author{
Codrut Sarafoleanu ${ }^{1,2,3}$, Alexis Vuzitas' ${ }^{1}$, Claudiu Manea ${ }^{1,2,3}$ \\ ${ }^{1}$ ENT\&HNS Department, "Sfanta Maria" Hospital, Bucharest, Romania \\ 2"Carol Davila" University of Medicine and Pharmacy, Bucharest, Romania \\ ${ }^{3}$ CESITO Center, "Sfanta Maria” Hospital, Bucharest, Romania
}

\begin{abstract}
Malignancies of the upper aerodigestive tract are high morbidity bearing and life-threatening diseases, which require thorough care from diagnostic suspicion and confirmation to surgical and/or oncologic treatment and rehabilitation. Difficulties in managing head and neck cancers arise from delays in diagnosis and treatment caused by either patient-related factors or healthcare system-related factors. Tumor origin and stage determine whether surgical excision is feasible, the approach required for safe excision, the extent of functional and aesthetic sacrifice required to attain oncologic safety and the need for reconstructive surgery. A thorough and systematic preoperative risk versus benefits assessment to select potential surgical candidates and give realistic outcomes is important from both a medical and a legal point of view. Because tumors in the head and neck region frequently involve more than one system and sensory organ, potential loss of function from either the disease course, surgical or nonsurgical treatment should be taken into account form a quality of life perspective. Effective management of head and neck cancer patients requires the cooperation and combined effort of a multidisciplinary team of surgeons, physicians and other workers over a long period of time which, in the absence of a specialised head and neck cancer centre and guidelines, can lead to increased morbidity and mortality, and patient dissatisfaction.
\end{abstract}

KEYWORDS: head and neck cancer, head and neck malignancy, oncologic surgery, upper aerodigestive tract cancer

\section{INTRODUCTION}

Cancers of the upper aero-digestive tract are responsible for more than 900,000 cases and 260,000 deaths each year ${ }^{1}$. The main risk factors involved in head and neck cancer are smoking, alcohol consumption and chronic viral infection such as HPV (Human Papillomavirus) and EBV (Epstein-Barr Virus) ${ }^{2}$.

Because head and neck cancers can alter the functionality of many systems and sensory organs, the goal of surgical and nonsurgical management is not only to cure and improve overall survival, but to do so while preserving their function and maintaining an adequate quality of life.

It is generally accepted today that head and neck cancers are best managed by a multidisciplinary team in a specialised head and neck cancer centre. The healthcare system should streamline the patients' course from clinical suspicion to diagnosis confirmation, surgical and/or oncologic treatment and functional rehabilitation ${ }^{3}$.
A number of factors make the surgical and oncologic management of patients with head and neck cancers difficult. This article presents the practical difficulties encountered in the management of these patients, from personal experience and reviewing the literature.

\section{DISEASE STAGE AT THE TIME OF FIRST PHYSICIAN APPOINTMENT VS DISEASE STAGE AT ADMISSION AND TREATMENT INITIATION}

In general, delays in diagnosis and treatment of head and neck cancers are linked to worse prognosis ${ }^{4}$. Delays up to 90 days do not decrease overall survival rates but may produce the need for more aggressive surgical treatment and thus increase morbidity ${ }^{5}$. Delays can be caused by patient-related factors (time lapse from symptoms onset to first physician appointment) as well as healthcare provider-related causes 
(time lapse from first physician appointment to correct diagnosis, which may include referral delays to head and neck specialists, and the time lapse from diagnosis to treatment). The average delay on patient's behalf ranges from days to years, while healthcare system-related delays range form days to months ${ }^{6}$. Factors associated with increased delays include nonsmokers, lack of referral to a specialist following the initial consultation, lack of regularly scheduled dentist appointments, hoarseness as the only symptom, while factors associated with timely diagnosis count in visible lesions, heavy drinking and smoking, odynophagia ${ }^{7,8}$. Patients' beliefs regarding the accuracy of the diagnosis, gravity of the disease, perceived treatment benefits and costs can influence conventional treatment initiation timing. Alternative medicine, as a first choice treatment, significantly delays conventional treatment and reduces the 3-year survival rate; patient characteristics associated with declining standard treatment include female gender, older age, single marital status, advanced tumour stage and significant comorbidities $^{9,10}$. Although pursuing second opinions increases time to treatment initiation, the increase in morbidity is negated by the improved survival rate at academic facilities ${ }^{11}$.

\section{SELECTING PATIENTS ELIGIBLE FOR SURGICAL TREATMENT}

Selecting realistic surgical candidates is a difficult task based on staging, anatomical landmarks involved, comorbidities, surgeon experience and technical means available. Tumor extension beyond the skull base (dura mater, endocranium) or to the spine, common and internal carotid artery may prevent complete resections and determine increased morbidity and are therefore considered contraindications ${ }^{12}$. Each approach (endoscopic, combined, or open) has its own limits and contraindications. Comorbidities such as a cardiovascular disease, respiratory disease, neurological diseases, diabetes, hematologic diseases, kidney and liver chronic diseases, alcohol or tobacco consumption have a greater negative impact for head and neck cancers than for other malignancies, thus stratifying the surgical risk and limiting therapeutic options $^{13,14}$. The nutritional status in any oncologic patient is important, and this is especially true in the head and neck region where the malignancy can directly impair swallowing. Percutaneous endoscopic gastrostomy is sometimes required to prevent malnutrition.

Neoadjuvant radiotherapy may deter some physicians from proposing surgery because it impairs wound healing and increases morbidity ${ }^{15}$. The most common example is the increased risk for pharyngocutaneous fistula in patients who underwent radiotherapy prior to total laryngectomy or laryngopharyngectomy ${ }^{16}$. The surgeon may address this potential complication by placing the tracheal stoma below the incision line in order to be uninvolved in the resulting wound ${ }^{17}$.

When surgically addressing head and neck cancers, also addressing the positive cervical lymph nodes via selective or radical neck dissections or oncologic treatment is an important part of the treatment plan; even infracentimetric lymph node metastases are a factor of poor prognosis ${ }^{18}$.

\section{PREOPERATIVE EVALUATION AND CHOOS- ING THE SURGICAL TECHNIQUE}

Preoperative evaluation of a head and neck cancer patient concludes with choosing the adequate surgical technique and should include:

Endoscopic examination of the upper aerodigestive tract is a mandatory procedure in head and neck cancer patients useful to assess potential surgical excision difficulties and risks and to screen for a second primary malignancy. A biopsy specimen can be acquired during an endoscopic evaluation; this can also be a source of error if, for example, it is taken from a necrotic part of the tumor, further delaying accurate diagnosis and treatment. In the case of a positive neck with an unknown primary, tonsillectomy, nasopharyngeal and tongue-base biopsies are advised before excisional biopsy of the lymph node is performed ${ }^{12,19}$.

Imaging. Cross-sectional imaging techniques (CT, MRI) are used to determine the tumor size and the involvement of adjacent structures. CT is better at appreciating bony erosions, while MRI is better at evaluating soft tissue involvement such as intracranial extension and differentiating between tumor, inflammation and secretions. PET-CT is currently the best imaging method in detecting recurrence. A particular case in the head and neck region is thyroid cancer, which may be assessed in early stages using ultrasonography and radionuclide imaging ${ }^{20}$. Ultrasonography is also considered the gold standard in diagnosing cervical lymph nodes, with better sensitivity and specificity than PET-CT ${ }^{21}$. Imaging can also be an important source of errors in head and neck cancer diagnosis and management (Figures 1, 2).

Functional evaluation of adjacent head and neck structures (sensory organs and their corresponding cranial nerves integrity, facial nerve function, swallowing, voice quality, oronasal breathing) before and after surgery is advised for both medical and legal reasons. Even if tumor resection is technically possible, the potential functional and aesthetic sacrifice required for oncologic safety might deter patients from opting for surgery. 

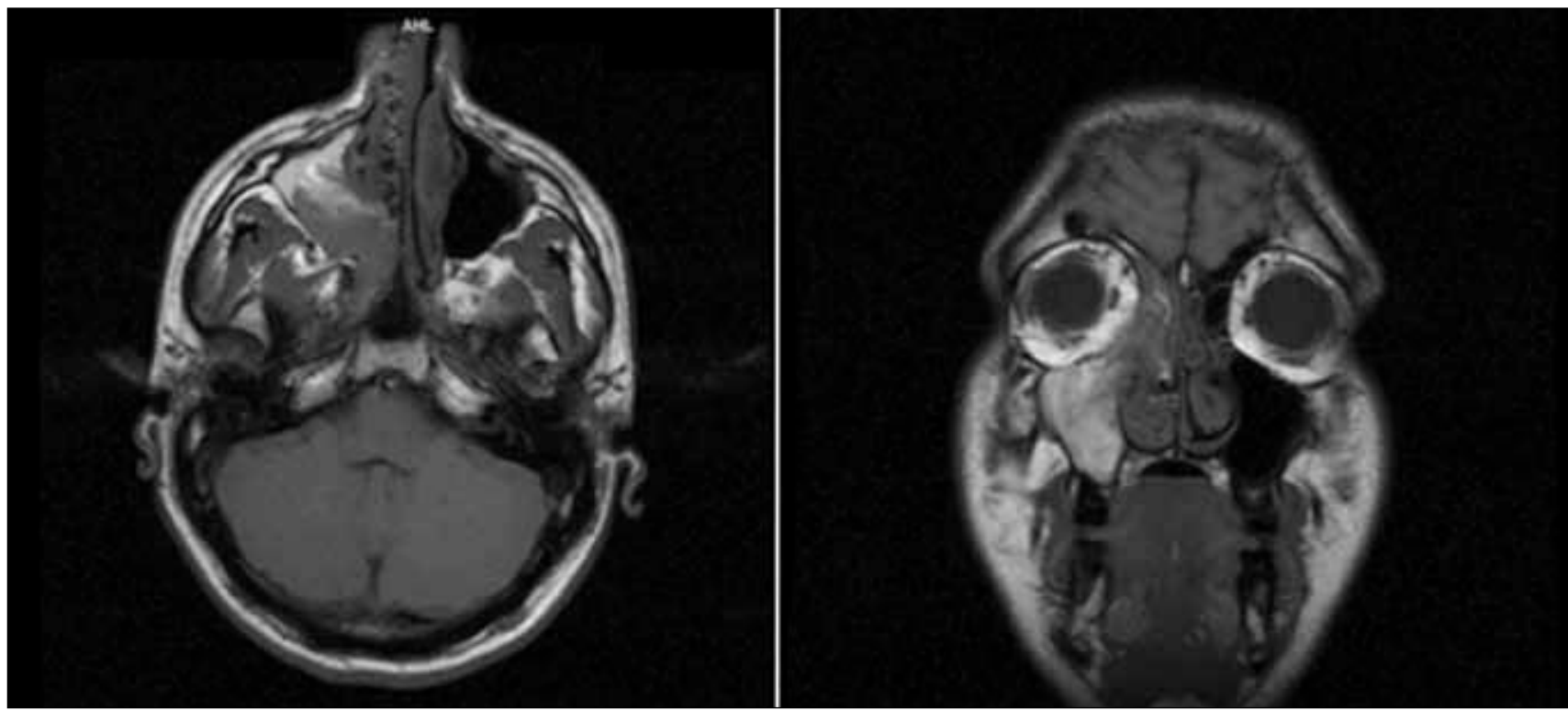

Figure 1 Cranio-facial MRI scan of a patient with malignancy of the right maxillary sinus. An anterior nasal packing procedure was performed prior to image acquisition due to epistaxis. The MRI features of the nasal packing may lead to diagnostic errors and incorrect appreciation of tumor extension.

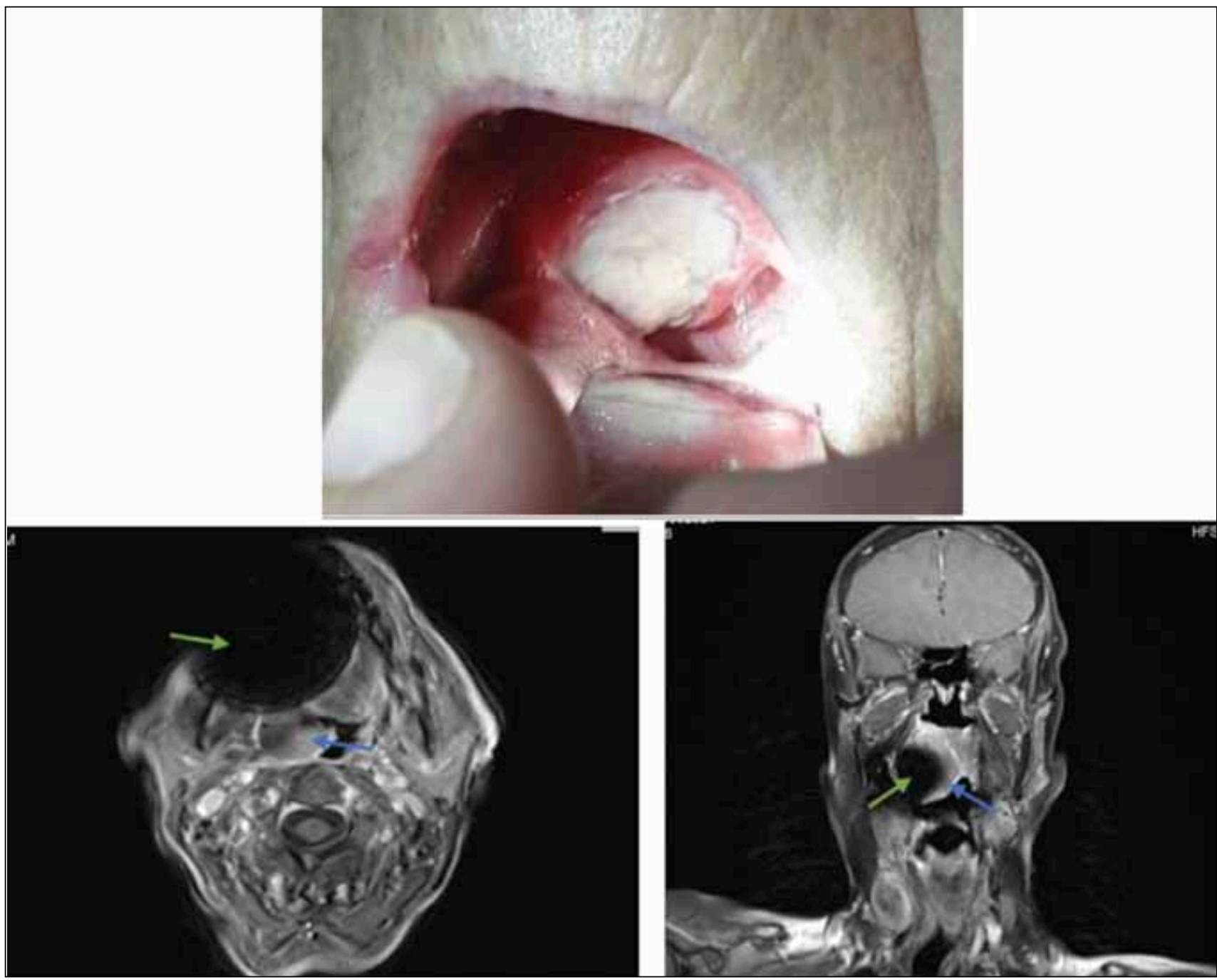

Figure 2 Right-sided palatine tonsil malignancy. MRI scan of the same patient shows the primary tumor (blue arrow) and a large magnetic susceptibility artefact due to a ferromagnetic dental implant (green arrow) which impedes proper evaluation of tumor extension. 


\section{RECONSTRUCTION OF TISSUE DEFECTS}

Head and neck cancer surgery frequently implies high tissue defects and increased morbidity in terms of both aesthetic and functional outcomes, pondering to the need for difficult reconstructive surgery in order to avoid complications such as malnutrition and negative psychological impact ${ }^{22}$.

Reconstructive surgery relies on grafts, local or regional flaps, free tissue transfer and synthetic materials of different consistencies for soft or bony tissue reconstruction. Free tissue transfer is considered the first choice for reconstruction in large tissue defects because it can restore integrity, function, as well as form, thus reducing morbidity and it is outside of the frequent preoperative radiation field ${ }^{23}$.

\section{PROVIDING THE BEST AVAILABLE HEALTHCARE FROM DIAGNOSIS TO REHABILITATION - THE MULTIDISCIPLINARY APPROACH}

Management of head and neck cancers from initial diagnosis onward involves many practitioners: head and neck surgeons as well as surgeons with different backgrounds (Figure 3), radiologists (both diagnostic and interventional), anaesthesiologist, clinical oncologist, radiation oncologist, pathologist, prosthodontist, psychotherapist, physical medicine and rehabilitation doctor, speech-language pathologist, family physician, social workers, caregivers.

Assembling a multidisciplinary team of both surgical and non-surgical medical specialities is time-consuming in the absence of a head and neck oncologic pathology centre. Most operating rooms are not pre- equipped with the necessary technical means to accommodate surgeons from multiple specialities. Legal aspects and the costs of planning an extensive multidisciplinary surgery should also be taken into account. However, multi-step surgery is often unfeasible and referring the patient from one physician to another without an integrated approach can result in patient dissatisfaction, reduced quality of life and decreased chances of survival ${ }^{25}$. Some health systems have published guidelines for creating effective multidisciplinary teams which dictate team membership and leadership, infrastructure and logistics, decision-making processes ${ }^{26}$.

Collaboration with the anaesthesiologist is important in order to approach potential airway-compromising tumours rendering orotracheal intubation difficult. Awake fiberoptic intubation or intubation via a tracheostomy is necessary in some cases, as is the intraoperative switch from orotracheal to tracheostomy intubation. In most cases, the airway must be shared between the surgeon(s) and the anaesthesiologist. Prolonged procedures also increase the difficulty and risk of general anaesthesia ${ }^{27,28}$.

Below are described five head and neck cancers types commonly seen in an ENT\&HNS Department:

\section{Sinonasal}

Many sinonasal malignancies, including squamous cell carcinoma, can be staged using the TNM classification. The Tumour (T) component is different depending on its origin, being either the maxillary sinus or the ethmoid sinus and the nasal cavity. The paucity of malignant tumours originating elsewhere (sphenoid sinus, frontal sinus) justifies their lack of generally accepted dedicated T stage ${ }^{17,29}$. The size of the tumour plays no role in Tumour staging, the focus being

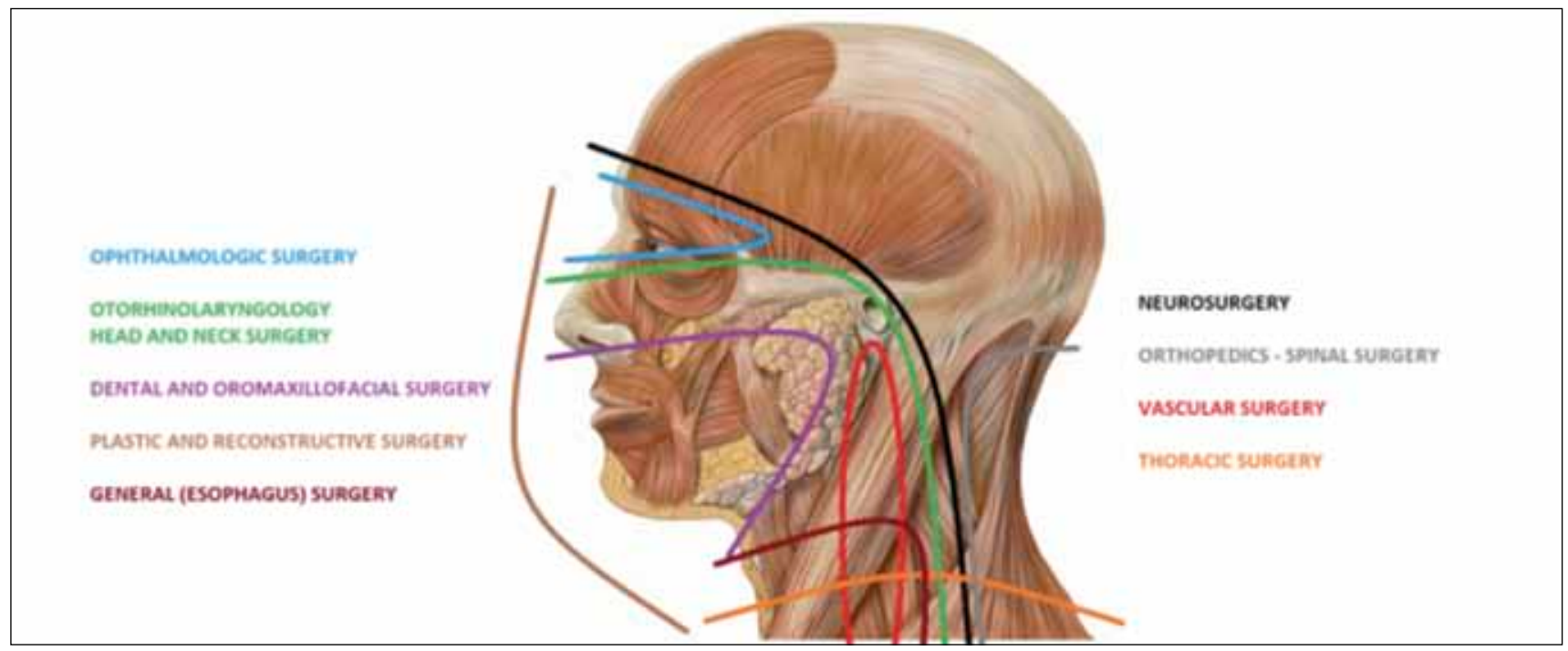

Figure 3 Surgeons involved in head and neck oncological pathology (Original picture: Head lateral anatomy created by Patrick J. Lynch. Acquired from https:// commons.wikimedia.org/wiki/File:Lateral_head_anatomy.jpg, under Creative Commons Attribution 2.5 License 2006 ${ }^{24}$ ). 
on the involvement of adjacent structures, while lymph Nodes $(\mathrm{N})$ are staged according to size and laterality $^{30,31}$. Other sinonasal malignancies have different staging systems, as are the cases of rhabdomyosarcoma which is staged into risk groups based on 3 systems: TNM, histologic classification and postoperative results or esthesioneuroblastoma which is staged according to Kadish-Morita histologic classification ${ }^{17,32}$.

The bulk of sinonasal malignancies benefit from combined surgical and oncological therapy. Few early stage tumours may benefit from standalone complete surgical excision, while in more advanced cases the surgical risks outweigh predicted benefits. Commonly accepted surgical limits include invasion of the carotid artery and cavernous sinus, optic chiasm, bilateral optic nerve or brain and M1 stage (M - metastasis). Commonly accepted surgical limits of endoscopic surgery include extension to orbital content, facial soft tissue, palate and areas beyond the reach of current optics and instrumentation. When carefully selecting patients, endoscopic sinus surgery for sinonasal malignancy has similar results compared to open surgery in terms of recurrence and overall survival ${ }^{33,34}$. Open approaches range from Caldwell-Luc to lateral rhinotomies, maxillectomies and anterior craniofacial resections with increasing functional and aesthetic deficits.

Reconstruction is necessary to prevent complications such as cerebrospinal fluid leak, to improve functional results of oral intake, speaking and vision and achieve aesthetic results to diminish psychological trauma. The techniques used include prostheses, obturation, pedicled and free flaps ${ }^{17,35,36}$.

To exemplify the difficulties in the surgical management of sinonasal tumors, we present a case of a 61-year-old woman who referred to our clinic for left nasal obstruction, rhinorrhea, repeated epistaxis, anosmia, left hemifacial paraesthesia, exophthalmos, epiphora and vision impairment in the left eye (Figure 4, Figure 5). The patient developed the symptoms over the course of the previous 6 months, during which she scheduled doctor appointments and underwent investigations.

Tumour excision was performed via an open lateral rhinotomy approach with cephalad Lynch extension and upper lip split for good intraoperative exposure (Figure 6).

\section{Nasopharyngeal cancer}

Nasopharyngeal cancer is usually diagnosed in an advanced stage. Incidental finding on head imaging is rare and up to three quarters of patients have cervical lymph node enlargement at initial presentation, higher than all head and neck squamous cell carcinomas $^{37,38}$. Nasopharyngeal biopsy can have false-negative results especially if no apparent lesion is observed in the nasopharynx. In a few situations, such as the case of positive neck and unknown primary, nasopharyngeal biopsies may need to be repeated with multiple fragments being obtained from the nasopharynx without missing the Rosenmuller fossa - the most common site of origin for nasopharyngeal carcinoma $^{39}$, nasopharyngeal dome or any slight mucosal asymmetry or discoloration ${ }^{17}$. Radiotherapy is the mainstay of treatment for nasopharyngeal carcinoma, with the possibility of adding chemotherapy for advanced stages. Side effects of radiotherapy are sometimes difficult to distinguish from disease recurrence (hearing loss, blood-stained sputum or nasal discharge, cranial nerve palsies $)^{40}$. Surgery is generally reserved for recurrent or residual disease and neck dissection. Nasopharyngectomy via an endoscopic or open approach is the surgical treatment of choice. Nasopharyngeal endoscopic resection of the posterior nasopharyngeal wall with possible extension superiorly to the sphenoid sinus or to the pterygoid plates and Eustachian tube while ensuring the integrity of the internal carotid artery is a less invasive approach with similar results to open procedures ${ }^{41}$. Open approaches include lateral rhinotomy with medial maxillectomy, maxillary swing, mid-facial degloving, infratemporal fossa approach, transpalatal approach ${ }^{42,43}$. Contraindications for nasopharyngectomy include invasion of the cavernous sinus, skull base erosion, intradural or intracranial invasion and pharyngobasilar fascia invasion; although it increases morbidity, a second course of preoperative radiotherapy is not considered an absolute contraindication ${ }^{44,45}$. Residual cervical lymph node disease can be managed by selective neck dissection when a single infracentimetric positive node is present or by radical neck dissection and individualised imaging-based modified neck dissection ${ }^{46,47}$. Palliative surgery including tumour debulking, electrocoagulation for epistaxis or myringotomy with grommet insertion for otitis media with effusion might alleviate symptoms, although the latter has been shown to increase the risk of difficult to manage otorrhea $^{48}$.

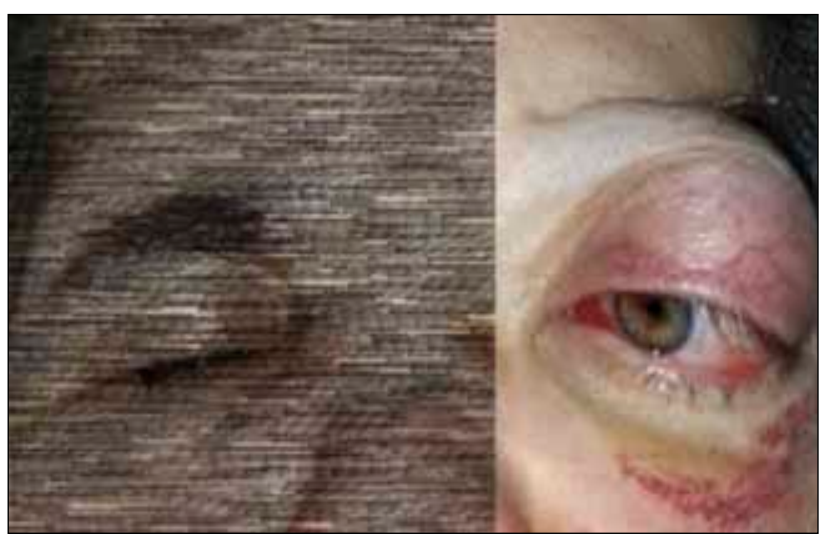

Figure 4 Left exophthalmos with chemosis. 


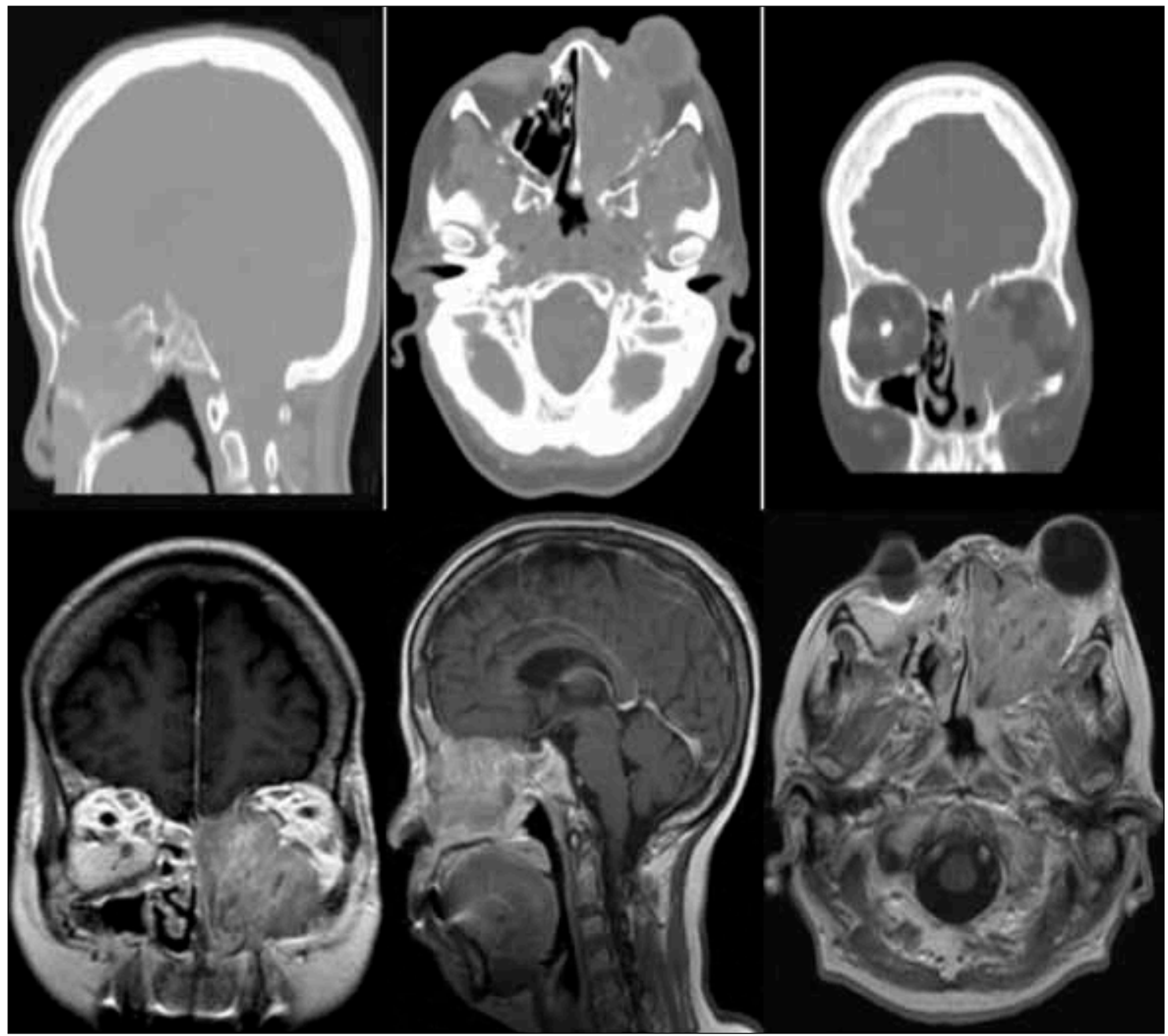

Figure 5 Cranio-facial CT scan and contrast enhanced MRI scan of the patient. Notice the extensive bony erosions caused by the tumor invading the ipsilateral orbit, extraocular muscles and optic nerve. This was especially important because the patient's left eye was the only functioning one (Notice the right eye prosthesis seen on the CT scan as a high density, rounded structure replacing the right globe. The patient has had an enucleation procedure performed for unrelated reasons). Erosion of the ethmoid roof can also be seen, without dural infiltration.

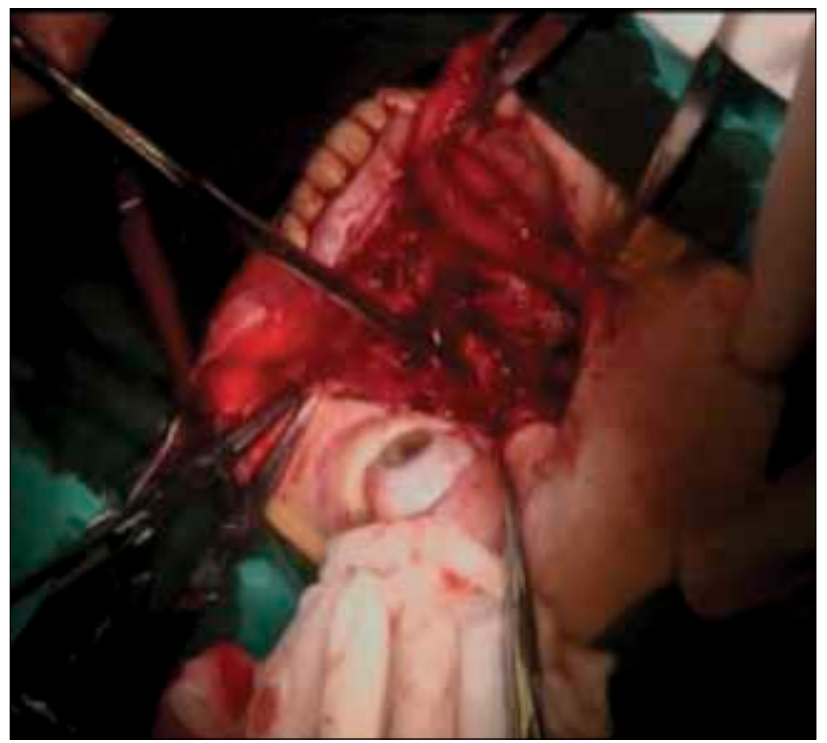

Figure 6 Intraoperatory view.

\section{Oropharyngeal (tonsillar) cancer}

For stage I or II tonsillar fossa carcinoma, both surgery and radiotherapy are equally effective in terms of local control ${ }^{49}$. Advanced lesions (stage III and IV) are currently best treated with surgery followed by radiotherapy with or without chemotherapy ${ }^{50,51}$. Tumour size, extension and involvement of adjacent structures as well as surgeon preference dictate the surgical approach. Most tonsillar fossa tumours can be managed using a transoral approach with the aid of radiofrequency, electrocautery, CO2 LASER or robotic assistance ${ }^{52,53}$. Some cases may require lateral pharyngotomy approach or lip-splitting anterior mandibulotomy for mandibular swing approach. Combined approaches such as transoral robotic surgery and lateral pharyngotomy with radial forearm free flap reconstruction may avoid the need for lip-splitting approach $^{54}$. Treatment for advanced disease might produce the need for temporary tracheostomy and gas- 
trostomy. The tonsillar node in the subdigastric group is the first one involved in tonsillar fossa cancer $^{55}$. If there is no clinical evidence of cervical lymph node involvement, a selective neck dissection should be performed. If radiotherapy is indicated postoperatively, an ipsilateral selective neck dissection in sufficient ${ }^{56}$. If the node stage of the disease is greater than 1 , radical neck dissection is advised ${ }^{57}$. Contraindications of tonsillar cancer surgery include inoperable neck disease, distant metastases, involvement of the carotid artery, skull base, spine, lateral pterygoid muscle, pterygoid plates, or paraspinous muscle ${ }^{58}$.

\section{Hypopharyngeal cancer}

Hypopharyngeal cancer has a worse prognosis compared to other squamous cell carcinomas of the head and neck, partly because of late diagnosis, frequent lymphatic and systemic metastases, frequent involvement of the larynx. Most hypopharyngeal cancers originate in the pyriform sinus, with fewer cases arising from the lateral or posterior pharyngeal wall and postcricoid space. Laryngeal preservation in hypopharyngeal cancer is a difficult task for the head and neck surgeon and, even with functional sacrifice, there are few surgical options. Although organ sparing techniques have, in general, low survival rates, for early lesions, transoral CO2 microresection seems to have good local control rates ${ }^{59,60}$. Open approaches include variations of hemilaryngopharyngectomy or, for advanced cases, total laryngectomy with partial pharyngectomy and variable esophagus ablation lengths ${ }^{61}$. Free flap reconstruction is required for extensive surgeries. For patients with no clinical cervical lymph node involvement a selective neck dissection of levels I-III may be sufficient, while the positive neck needs to be addressed with a level I through $\mathrm{V}$ selective neck dissection ${ }^{62}$.

\section{Laryngeal cancer}

The surgical approach for laryngeal cancer is influenced by the TNM classification and the subsite of origin. Early glottic squamous cell carcinoma (in situ, T1, T2) can be managed with radiotherapy or surgical excision, the latter keeping both treatment options (radiotherapy and salvage surgery) available in case of recurrence. Surgical approaches include transoral laser microlaryngoscopy with partial, complete or extended cordectomy and open approaches: cordectomy through laryngofissure, frontolateral partial laryngectomy, hemilaryngectomy, subtotal laryngectomy with cricohyoidoepiglottopexy ${ }^{17}$. Excisional biopsies may be curative in some CIS (carcinoma in situ) cases if they achieve clear surgical margins ${ }^{63}$. Early supraglottic tumours $(\mathrm{T} 1, \mathrm{~T} 2)$ are amendable by transoral laser microsurgery, supraglottic laryngectomy or supracricoid laryngectomy with cricohyoidopexy. One of the most important principles of open organ sparing surgery is preserving at least one cricoarytenoid unit as the functional unit of the larynx in order to keep the respiratory and digestive paths separated ${ }^{64}$. Transoral laser microsurgery is currently expanding its indications for progressively more advanced laryngeal cancer rivalling the most extensive function preserving open approaches like the supracricoid partial laryngectomy. Because of the good oncologic safety, functional outcome and low morbidity and mortality, transoral laser microsurgery is a viable treatment option in selected T2-T4 laryngeal carcinomas ${ }^{65}$. When organ sparing surgery is not compatible with tumour extension or does not have acceptable local control rates, as is the case of complete endolaryngeal obstruction, some bilateral and transglottic tumours, bilateral cricoarytenoid joint involvement, subglottic extension, invasion of extralaryngeal tissue or non-squamous cell malignancies, total laryngectomy is indicated ${ }^{66}$. The procedure reduces the quality of life of recipients in terms of voice loss (which can be improved by tracheoesophageal puncture), dysphagia (amendable by rehabilitation), anosmia, risk of aspiration and drowning, psychological and social impact ${ }^{67-69}$. Cervical lymphadenectomy for the clinically negative neck in terms of selective neck dissection of levels II through IV is currently indicated starting from T2 tumours involving the suprahyoid epiglottis, T3 supraglottic and T4 glottic tumours ${ }^{70}$.

\section{CONCLUSIONS}

1. Increased awareness in both the general population and healthcare professionals regarding head and neck cancers may facilitate early access of patients to diagnostic and therapeutic procedures. Considering the wide range of surgical procedures available, from minimally invasive to extensive resections, early diagnosis of head and neck malignancies becomes important not only for improving survival rates but also for decreasing morbidity and increasing the quality of life.

2. A thorough preoperative assessment is of utmost importance in selecting realistic surgical candidates, preventing intraoperative accidents and postoperative complications and providing the patient with a predicted oncologic and functional outcome.

3. A guideline based multidisciplinary approach in an academic head and neck cancer centre currently provides the best outcomes for patients with upper aerodigestive tract malignancies.

4. Surgery plays a central role in addressing many upper aerodigestive tract malignancies, but the overall management of such a patient from diagnostic to rehabilitation and social reintegration determines the medical and psychological success. 


\section{Conflict of interest: The authors have no conflict of interest. \\ Contribution of authors: All authors have equally contributed to this work.}

\section{REFERENCES}

1. Global Burden of Disease Cancer Collaboration, Fitzmaurice C., Allen C., Barber R.M., Barregard L., Bhutta Z.A., Brenner H., Dicker D.J., et al. Global, Regional, and National Cancer Incidence, Mortality, Years of Life Lost, Years Lived With Disability, and Disability-Adjusted Life-years for 32 Cancer Groups, 1990 to 2015: A Systematic Analysis for the Global Burden of Disease Study. JAMA Oncol., 2017;3(4):524-548. doi: 10.1001/ jamaoncol.2016.5688.

2. Stenson K.M. - Epidemiology and risk factors for head and neck cancer. Available at http:/ / www.uptodate.com/contents/epidemiology-and-riskfactors-for-head-and-neck-cancer. Accessed June 16, 2017.

3. Collins R., Flynn A., Melville A., Richardson R., Eastwood A. - Effective health care: management of head and neck cancers. Qual Saf Health Care, 2005;14(2):144-148. doi: 10.1136/qshc.2005.013961.

4. Shepphird J. - Treatment delay linked with worse outcome for head and neck cancer. Oncology Practice. December 7, 2015.

5. van Harten M.C., de Ridder M., Hamming-Vrieze O., Smeele L.E., Balm A.J., van den Brekel M.W. - The association of treatment delay and prognosis in head and neck squamous cell carcinoma (HNSCC) patients in a Dutch comprehensive cancer center. Oral Oncol., 2014;50(4):282-290. doi: 10.1016/j.oraloncology.2013.12.018. Epub 2014 Jan 7.

6. Lee S.C., Tang I.P., Avatar S.P., Ahmad N., Selva K.S., Tay K.K., Vikneswaran T., Tan T.Y. - Head and neck cancer: possible causes for delay in diagnosis and treatment. Med J Malaysia., 2011;66(2):101-104.

7. Brouha X.D., Tromp D.M., Koole R., Hordijk G.J., Winnubst J.A., de Leeuw J.R. - Professional delay in head and neck cancer patients: analysis of the diagnostic pathway. Oral Oncol., 2007;43(6):551-556.

8. Yu T., Wood R.E., Tenenbaum H.C. - Delays in diagnosis of head and neck cancers. J Can Dent Assoc., 2008;74(1):61.

9. Dronkers E.A.C., Mes S.W., Wieringa M.H., van der Schroeff M.P., Baatenburg de Jog R.J. - Noncompliance to guidelines in head and neck cancer treatment; associated factors for both patient and physician. BMC Cancer, 2015;15(1):1-10.

10. Davis G.E., Bryson C.L., Yueh B., McDonell M.B., Micek M.A., Fihn S.D. - Treatment delay associated with alternative medicine use among veterans with head and neck cancer. Head Neck, 2006;28(10):926-931.

11. Murphy C.T., Galloway T.J., Handorf E.A., Egleston B.L., Wang L.S., Mehra R., Flieder D.B., Ridge J.A. - Survival impact of increasing time to treatment initiation for patients with head and neck cancer in the United States. J Clin Oncol., 2016;34(2):169-178.

12. Harréus U. - Surgical errors and risks - the head and neck cancer patient. GMS Curr Top Otorhinolaryngol Head Neck Surg., 2013;12:Doc04. Published online 2013 Dec 13. doi: 10.3205/cto000096.

13. Piccirillo J.F. - Importance of comorbidity in head and neck cancer. Laryngoscope, 2000;110(4):593-602. doi: 10.1097/00005537-20000400000011.

14. Robson A., Sturman J., Williamson P., Conboy P., Penney S., Wood H. Pre-treatment clinical assessment in head and neck cancer: United Kingdom National Multidisciplinary Guidelines. J Laryngol Otol., 2016;130(Suppl 2):S13-S22.

15. Haubner F., Ohmann E., Pohl F., Strutz J., Gassner H.G. - Wound healing after radiation therapy: Review of the literature. Radiat Oncol., 2012;7:162. doi: 10.1186/1748-717X-7-162.

16. Clark J.H., Feng A.L., Morton K., Agrawal N., Richmon J.D. - Neck inci- sion planning for total laryngectomy with pharyngectomy. Otolaryngol Head Neck Surg., 2016;154(4):650-656.

17. Flint P.W. - Cummings Otolaryngology: Head and Neck Surgery. Saunders; 6 edition, 2014.

18. Pauzie A., Gavid M., Dumollard J.M., Timoshenko A., Peoc'h M., Prades J.M. - Infracentimetric cervical lymph node metastasis in head and neck squamous cell carcinoma: Incidence and prognostic value. Eur Ann Otorhinolaryngol Head Neck Dis., 2016;133(5):307-311. doi: 10.1016/j. anorl.2016.05.009. Epub 2016 Jul 27.

19. McGuirt W.F. - Panendoscopy as a screening examination for simultaneous primary tumors in head and neck cancer: a prospective sequential study and review of the literature. Laryngoscope, 1982;92(5):569-576.

20. Patkar D., Yanamandala R., Lawande M. - Imaging in head and neck cancers. Otorhinolaryngology Clinics: An International Journal, 2010;2(1):15-23. doi: 10.5005/jp-journals-10003-1013.

21. Ashraf M., Biswas J., Jha J., Nayak S., Singh V., Majumdar S., Bhowmick A., Dam A. - Clinical utility and prospective comparison of ultrasonography and computed tomography imaging in staging of neck metastases in head and neck squamous cell cancer in an Indian setup. Int J Clin Oncol., 2011;16(6):686-693. doi: 10.1007/s10147-011-0250-2.

22. Lin S.J. - Head and Neck Cancer - Reconstruction. Available at: http:// emedicine.medscape.com/article/1289799-overview\#a1. Accessed June $17,2017$.

23. Chim H., Salgado C.J., Seselgyte R., Wei F.C., Mardini S. - Principles of head and neck reconstruction: an algorithm to guide flap selection. Semin Plast Surg., 2010;24(2):148-154. doi: 10.1055/s-0030-1255332.

24. Original picture: Head lateral anatomy created by Patrick J. Lynch. Acquired form https://commons.wikimedia.org/wiki/File:Lateral_ head_anatomy.jpg, under Creative Commons Attribution 2.5 License 2006.

25. Abdulrahman G.O. - The effect of multidisciplinary team care on cancer management. Pan Afr Med J., 2011;9:20.

26. National Cancer Action Team NHS - The characteristics of an effective multidisciplinary team (MDT). February 2010;p.1-10.

27. Charters P., Ahmad I., Patel A., Russell S. - Anaesthesia for head and neck surgery: United Kingdom National Multidisciplinary Guidelines. J Laryngol Otol., 2016;130(Suppl 2):S23-S27.

28. Supkis D.E. Jr, Dougherty T.B., Nguyen D.T., Cagle C.K. - Anesthetic management of the patient undergoing head and neck cancer surgery. Int Anesthesiol Clin., 1998;36(3):21-29.

29. American Joint Committee on Cancer - Nasal cavity and paranasal sinuses. In: AJCC Cancer Staging Manual. 7th ed. New York, NY: Springer, 2010;p.69-73.

30. Stevenson M.M. - Nasal cavity and paranasal sinuses cancer staging. Available at http://emedicine.medscape.com/article/2047703-overview. Accessed June 15, 2017.

31. Deschler D.G., Moore M.G., Smith R.V., eds. - Quick reference guide to TNM staging of head and neck cancer and neck dissection classification. 4th ed. Alexandria, VA: American Academy of Otolaryngology-Head and Neck Surgery Foundation, 2014.

32. Bell D., Saade R., Roberts D., Ow T.J., Kupferman M., DeMonte F., Hanna E.Y. - Prognostic utility of Hyams histological grading and Kadish-Morita staging systems for esthesioneuroblastoma outcomes. Head Neck Pathol., 2015;9(1):51-59.

33. Saedi B., Aghili M., Motiee M., Valadkhani S., Niazi A.B., Safavi A. Surgical outcomes of malignant sinonasal tumours: open versus endoscopic surgical approaches. J Laryngol Otol., 2014;128(9):784-790. doi: 10.1017/S0022215114001583. Epub 2014 Jul 31.

34. Suh J.D., Ramakrishnan V.R., Chi J.J., Palmer J.N., Chiu A.G. - Outcomes and complications of endoscopic approaches for malignancies of the paranasal sinuses and anterior skull base. Ann Otol Rhinol Laryngol., 2013;122(1):54-59. 
35. Battaglia P., Turri-Zanoni M., De Bernardi F., Dehgani Mobaraki P., Karligkiotis A., Leone F., Castelnuovo P. - Septal flip flap for anterior skull base reconstruction after endoscopic resection of sinonasal cancers: preliminary outcomes. Acta Otorhinolaryngol Ital., 2016;36(3):194-198. doi: 10.14639/0392-100X-748.

36. Suárez C., Ferlito A., Lund V.J., Silver C.E., Fagan J.J., Rodrigo J.P., Llorente J.L., Cantu G., Politi M., Wei W.I., Rinaldo A. - Management of the orbit in malignant sinonasal tumors. Head Neck, 2008;30(2):242-250.

37. Ho F.C.H., Tham I.W., Earnest A., Lee K.M., Lu J.J. - Patterns of regional lymph node metastasis of nasopharyngeal carcinoma: a meta-analysis of clinical evidence. BMC Cancer, 2012;12:98. Published online 2012 Mar 21. doi: 10.1186/1471-2407-12-98.

38. Sham J.S., Choy D., Wei W.I. - Nasopharyngeal carcinoma: orderly neck node spread. Int J Radiat Oncol Biol Phys., 1990;19(4):929-933.

39. Sham J.S., Wei W.I., Zong Y.S., Choy D., Guo Y.Q., Luo Y., Lin Z.X., Ng M.H. - Detection of subclinical nasopharyngeal carcinoma by fibreoptic endoscopy and multiple biopsy. Lancet, 1990;335(8686):371-374.

40. Canadian Cancer Society - Side effects of radiation therapy for nasopharyngeal cancer. Available at http://www.cancer.ca/en/cancer-information/cancer-type/nasopharyngeal/treatment/radiation-therapy/potential-side-effects. Accessed June 10, 2017.

41. Castelnuovo P., Nicolai P., Turri-Zanoni M., Battaglia P., Bolzoni Vollaret A., Gallo S., Bignami M., Dallan I. - Endoscopic endonasal nasopharyngectomy in selected cancers. Otolaryngol Head Neck Surg., 2013;149(3):424-430. doi: 10.1177/0194599813493073. Epub 2013 Jun 13.

42. Tsang R.K., Wi W.I. - Salvage surgery for nasopharyngeal cancer. World Journal of Otorhinolaryngology-Head and Neck Surgery, 2015;1(1):34-43.

43. Vlantis L.A.C. - Maxillary swing approach to the nasopharynx. Open access atlas of otolaryngology, head \& neck operative surgery. Available at https://vula.uct.ac.za/access/content/group/ba5fblbd-be95-48e581 be-586fbaeba29d/Maxillary\%20Swing\%20approach\%20to\%20 the\%20nasopharynx.pdf. Accessed June 12, 2017

44. Suárez C., Rodrigo J.P., Rinaldo A., Langendijk J.A., Shaha A.R., Ferlito A. - Current treatment options for recurrent nasopharyngeal cancer. Eur Arch Otorhinolaryngol., 2010;267(12):1811-1824. doi: 10.1007/s00405010-1385-x

45. Hao S.P., Tsang N.M., Chang C.N. - Salvage surgery for recurrent nasopharyngeal carcinoma. Arch Otolaryngol Head Neck Surg., 2002;128(1):63-67.

46. Chen J.Y., Zhang L., Ji Q.H., Li D.S., Shen Q., Wang Z.Y., Huang C.P., Wang Y., Zhu Y.X. - Selective neck dissection for neck residue of nasopharyngeal carcinoma: A prospective study. J Craniomaxillofac Surg., 2015;43(8):1571-1576. doi: 10.1016/j.jcms.2015.06.037. Epub 2015 Jul 10.

47. Peng H., Wang S.J., Yang X., Lin J., Guo H., Liu M. - Modified radical neck dissection for residual neck disease after radiotherapy of nasopharyngeal carcinoma. Auris Nasus Larynx., 2014;41(5):485-490. doi: 10.1016/j.anl.2014.05.018. Epub 2014 Jun 10.

48. Ho W.K., Wei W.I., Yuen A.P., Hui Y., Wong S.H. - Otorrhea after grommet insertion for middle ear effusion in patients with nasopharyngeal carcinoma. Am J Otolaryngol., 1999;20(1):12-15.

49. Hicks W.L. Jr, Kuriakose M.A., Loree T.R., Orner J.B., Schwartz G., Mullins A., Donaldson C., Winston J.M., Bakamjian V.Y. - Surgery versus radiation therapy as single-modality treatment of tonsillar fossa carcinoma: the Roswell Park Cancer Institute experience (1971-1991). Laryngoscope, 1998;108(7):1014-1019.

50. Foote R.L., Hilgenfeld R.U., Kunselman S.J., Schaid D.J., Buskirk S.J., Grado G.L., Earle J.D. - Radiation therapy for squamous cell carcinoma of the tonsil. Mayo Clin Proc., 1994;69(6):525-531.
51. Zelefsky M.J., Harrison L.B., Armstrong J.G. - Long-term treatment results of postoperative radiation therapy for advanced stage oropharyngeal carcinoma. Cancer, 1992;70(10):2388-2395.

52. Holsinger F.C., McWhorter A.J., Menard M., Garcia D., Laccourreve O. - Transoral lateral oropharyngectomy for squamous cell carcinoma of the tonsillar region: I. Technique, complications, and functional results. Arch Otolaryngol Head Neck Surg., 2005;131(7):583-591.

53. Weinstein G.S., O’Malley B.W. Jr, Snyder W., Sherman E., Quon H. Transoral robotic surgery: radical tonsillectomy. Arch Otolaryngol Head Neck Surg., 2007;133(12):1220-1226.

54. Biron V.L., O'Connell D.A., Barber B., Clark J.M., Andrews C., Jeffery C.C., Cote D.W., Harris J., Seikaly H. - Transoral robotic surgery with radial forearm free flap reconstruction: case control analysis. J Otolaryngol Head Neck Surg., 2017;46(1):20. doi: 10.1186/s40463-017-0196-0.

55. Van Abel K.M., Moore J. - Focus Issue: Neck Dissection for Oropharyngeal Squamous Cell Carcinoma. ISRN Surgery Volume 2012, Article ID 547017, 10 pages. doi: 10.5402/2012/547017.

56. Robbins K.T. - Indications for selective neck dissection: when, how, and why. Oncology (Williston Park), 2000;14(10):1455-1464; discussion 1467-1469.

57. Jones A.S., Fenton J.E., Husband D.J. - The treatment of squamous cell carcinoma of the tonsil with neck node metastases. Head Neck., 2003;25(1):24-31.

58. Kokot N. - Malignant tonsil tumor surgery. Available at http://emedicine.medscape.com/article/848034-overview\#a13. Accessed June 15, 2017.

59. Vilaseca I., Blanch J.L., Bernal-Sprekelsen M. - Transoral laser surgery for hypopharyngeal carcinomas. Curr Opin Otolaryngol Head Neck Surg., 2012;20(2):97-102. doi: 10.1097/MOO.0b013e32834fa8fe.

60. Mura F., Bertino G., Occhini A., Benazzo M. - Surgical treatment of hypopharyngeal cancer: a review of the literature and proposal for a decisional flow-chart. Acta Otorhinolaryngol Ital., 2013;33(5):299-306.

61. Quon H. - Hypopharyngeal cancer. Available at http://emedicine.medscape.com/article/1375268-overview\#a8. Accessed June 18, 2017.

62. Cong T., Zhao E., Xiao S., Wang Q., Wu Y., Shen H., Li T., Qin Y. Selective neck dissection and the management of the hypopharyngeal cancer. Lin Chung Er Bi Yan Hou Tou Jing Wai Ke Za Zhi., 2012;26(6):241-244.

63. Jackel M.C., Ambrosch P., Martin A., Steiner W. - Impact of re-resection for inadequate margins on the prognosis of upper aerodigestive tract cancer treated by laser microsurgery. Laryngoscope., 2007;117(2):350-356.

64. Chawla S., Carney A.S. - Organ preservation surgery for laryngeal cancer. Head Neck Oncol., 2009;1:12. doi: 10.1186/1758-3284-1-12.

65. Hinni M.L., Salassa J.R., Grant D.G., Pearson B.W., Hayden R.E., Martin A., Christiansen H., Haughey B.H., Nussenbaum B., Steiner W. Transoral laser microsurgery for advanced laryngeal cancer. Arch Otolaryngol Head Neck Surg., 2007;133(12):1198-1204.

66. Ceachir O., Hainarosie R., Zainea V. - Total laryngectomy - past, present, future. Maedica (Buchar)., 2014;9(2):210-216.

67. Sarafoleanu C. (coord.) - Tulburarile de deglutitie - de la etiologie la recuperare functionala. Editura Academiei Romane, Bucuresti, 2017.

68. Schwartz D.N., Mozell M.M., Youngentob S.L., Leopold D.L., Sheehe P.R. - Improvement of olfaction in laryngectomized patients with the larynx bypass. Laryngoscope, 1987;97(11):1280-1286.

69. Gray R.F. - Swimming after laryngectomy. Laryngoscope, 1982;92(7 Pt 1):815-817.

70. Deganello A., et al. - Effectiveness and pitfalls of elective neck dissection in N0 laryngeal cancer. Acta Otorhinolaryngol Ital., 2011;31(4):216-221. 